\title{
8
}

\section{International Donors and Social Policy Diffusion in the Global South}

\author{
Marina Dodlova
}

\section{Introduction}

In the past decades, the bulks of development assistance received by the Global South have been channeled through bilateral aid agencies, multilateral development banks, United Nations (UN) programs and other donor structures and international financial institutions (IFIs). Donor assistance is especially important, as in most cases the national governments' resources are not sufficient to meet specific sectoral targets agreed upon by the international community and ratified by developing countries (Hagen-Zanker and McCord 2013).

This considerable support and the close relationship between the two sides lead to a state in which international donors may exert substantial influence on the pro-poor policies of recipient countries (e.g. Kilby 2006; Khan et al. 2018). Donors often have opportunities to consult on the design and implementation of social policies, provide expertise for

\footnotetext{
M. Dodlova $(\bowtie)$

Department for Development Economics, University of Passau, CESifo, Passau, Germany 
different contexts, impact national policy agendas through external funding and direct their priorities to national policy-makers. Additionally, there is evidence that donor influence might be strong in areas such as health policy (Groves and Hinton 2013), even in the absence of sizable funding. Hence, the IFIs not only provide funds for reducing poverty and vulnerability but also may shape the long-term course of development.

However, while scholars and practitioners acknowledge the contextual differences in poverty alleviation and development outcomes across recipients, the specific role of donors in the formulation and implementation of social policies they finance and support in poor countries remains unclear. Unlike previous research on the effects of the institutions of recipient countries, the systematic policy patterns across donor organizations have been little explored.

This chapter is one of the first attempts to quantitatively investigate systematic patterns of the role of donors in determining the social policy agendas of recipient countries. More specifically, we reveal the impact of IFIs on the types and designs of social assistance programs in developing countries. We argue that international organizations such as the World Bank, European Commission, United Nations International Children's Emergency Fund (UNICEF) and other IFIs can encourage or pressure national governments to adopt specific types of pro-poor policies or even define the components of social transfer programs according to their own agendas. We hypothesize that IFIs increase the adoption of social transfers in total and, in addition, may choose specific types of programs or certain mechanisms of targeting. For example, they may promote conditional social transfers because they imply human capital investments by beneficiaries. ${ }^{1}$ The donors can provide substantial technical expertise and other resources for increasing administrative capacity so that national policy-makers can afford to operationalize more complex programs. At the same time, IFIs may also pursue strategic interests in the provision of social assistance, especially in the form of specific policies such as public works programs. We will discuss some of these potential trade-offs in social policy-making.

\footnotetext{
${ }^{1}$ Conditions are behavioral rules that should be compiled by beneficiaries for collecting social transfers. As conditions are typically introduced for education and health care, conditional programs are regarded as poverty alleviation policies with encouraged investments in human capital.
} 
We use two main sources of information. We extract the data from the non-contributory social transfer programs (NSTP, Version 1.1, 2017) and UNU-WIDER Social Assistance, Politics and Institutions (SAPI, Version 1.0, 2018) data sets on social transfers in the developing world. In total, we consider 155 programs in 84 countries, 35\% of which have at least one donor involved. The period considered covers the period from 1960 to the year of program adoption, which allows us to focus on the adoption process of social transfer programs and the role of donors in this process. The sample consists of countries with at least one program in operation.

We focus on the types of programs, conditionalities, targeting mechanisms and the details of donor assistance. We classify all programs according to four types: unconditional social pensions, family allowance, conditional cash transfers (CCTs) and employment guarantee schemes. If a program shows elements of two or three types, it is assigned to every applicable type. In addition, we contrast conditional and unconditional transfers in order to trace the extent to which donors care about conditionalities as an instrument for human capital investment. Then we distinguish between six targeting mechanisms: community-based, categorical, geographical, means testing, proxy means testing and selftargeting. We test the hypotheses that IFIs may prefer specific types of social transfer programs, in particular conditional versus unconditional schemes, or certain selection mechanisms that are used to target those among the extreme poor that are most deserving of social benefits. Donors may influence the choice of social transfer programs in order to prioritize their own policy agenda or to facilitate program implementation and operationalization based on their own administrative capacities.

We find that donors have several preferences concerning the choice of both program type and targeting method. In particular, we show that IFIs promote CCTs, family support programs and public works programs, whereas social pensions remain popular in all developing countries, regardless of donor assistance. We also find different preferences among the donors. While the World Bank follows the general pattern and favors all program types except social pensions, UNICEF typically promotes family allowances. This is consistent with the hypothesis that the donors' policies are in line with their own organization's priorities. 
Interestingly, conditionalities are promoted only by the World Bank and not by all donors, as might be expected. This might be due to enforcement difficulties and the limited state capacity in recipient countries. Regarding targeting, community-based programs prove to be the most favored ones, as external donors need to rely on the expertise of local community members. We also show that proxy means testing is promoted by the World Bank. This might be explained by the close relationship between the World Bank and recipient countries, or by the large administrative and technical capacity required for implementing proxy means tests, which can be provided by the World Bank. UNICEF and the UK Department for International Development (DFID) more frequently use categorical and geographical targeting, as they primarily favor family support programs. Similarly, the World Food Programme (WFP) more frequently applies geographical targeting and self-selection mechanisms. These findings generally support the hypothesis that international donors exhibit a coercive nature when it comes to social policy diffusion in developing countries.

This chapter is structured as follows. The next two Sections give an overview of the relevant literature and theoretical considerations. We then present the data and the methodology. The following Section reports the impact of donors on the types of social assistance. Then we present our findings on how the donors influence the design of social transfer programs, in particular targeting mechanisms. The last Section discusses policy implications and contains concluding remarks.

\section{Relevant Literature}

Despite broad research on the effectiveness of foreign aid and the reasons behind persistent poverty in developing countries, little is known about the donor-side factors affecting long-term development. Given the donors' power in shaping the goals of social policy, implementation and effectiveness of aid programs, a systematic investigation of their strategic interests, capacities and pursued policy models becomes vital for understanding the failures and inefficiency of aid in developing countries.

It has been shown that the quality of donors may significantly influence both the volumes of development assistance and its effectiveness. 
For example, Minasyan et al. (2017) demonstrate that only qualityadjusted aid leads to increasing GDP per capita in recipient countries. The authors base their findings on the donor performance index of the Center for Global Development. However, such overall rankings of aid donors, even across sectors, may be misleading due to measurement errors and construction biases. A more detailed analysis of the components of the donor-recipient relationship helps to gain a better understanding of how donor characteristics and policies influence development outcomes.

Some evidence on the impacts of donor qualities is available from the literature focusing on the political economy of foreign aid. Fuchs and Richert (2018) show that the personalities of ministers in a donor country may affect foreign aid giving. Female ministers with previous experience in development cooperation provide a higher quality of development assistance. Additionally, Hicks et al. (2016) present evidence that female political representation in donor countries increases foreign aid.

Furthermore, political ideology and dominant party platforms in donor countries matter for aid allocation (Dreher et al. 2015; Milner and Tingley 2010; Thérien and Noel 2000; Cashel-Cordo and Craig 1997). Dreher et al. (2015), for example, analyze the shifts in the dominant political orientation of German governments back and forth from conservative to socialist in 1973-2010 and find that the socialist leadership decreases aid commitments. On the other hand, Brech and Potrafke (2014) show that left-leaning governments increase bilateral aid, especially if it is allocated to least developed countries. Milner and Tingley (2010) also demonstrate that the allocation of US aid depends, among other things, upon the left-right ideological predisposition of legislators voting for the distribution of aid. Fuchs et al. (2014) conclude that economic interests, colonial past, terror incidents and aid inertia determine donor generosity. Harrigan et al. (2006) argue that aid allocations to the Middle East and North Africa (MENA) are likely to be influenced by US interests in the region. Donor ideology can also influence aid delivery strategies. In particular, Allen and Flynn (2018) find that more liberal governments tend to channel aid through non-governmental organizations (NGOs), probably with the purpose of inducing a direct effect on poverty alleviation in recipient countries, while more conservative 
governments prefer government-to-government channels that take economic and geopolitical interests into account.

Many other studies have explored how donors' interests shape the influx of foreign aid into recipient nations, as well as the effectiveness of that aid (Alesina and Dollar 2000; Berthélemy 2006; Dreher et al. 2008; Faye and Niehaus 2012; Hicks et al. 2016; etc.). In particular, Faye and Niehaus (2012) show that countries that are more politically aligned with donors receive more aid during election years, whereas there is no such effect in less aligned recipient countries. Dreher et al. (2008) conclude that the type of aid provided by the US depends on its ability to induce political support by recipients. Several other studies present evidence that "political" aid is allocated to meet political goals or to please political allies. Vreeland and Dreher (2014) demonstrate that United Nations Security Council (UNSC) membership is a critical factor for the distribution of foreign aid. In particular, developed countries may direct financial flows to UNSC members who, in return, provide political support. Dreher et al. (2009) find a positive relationship between temporary UNSC membership and the number of World Bank development projects implemented within a country, although the total aid budget of these projects does not change significantly. Dreher et al. (2018) find that aid to countries temporarily serving on the UNSC is less effective compared to aid received at other times. Moreover, Dreher et al. (2019) present evidence that the amount of development assistance provided by the Chinese government is determined by co-ethnicity and favoritism that is based upon the birth regions of African leaders. It is therefore obvious that the argument regarding the influence of recipient qualities and donor interests in aid allocation has found large support in the literature on foreign aid (Becker, Chap. 7, this volume).

Additionally, the literature further elaborates on the policies pursued by international donors. For example, Bodenstein and Kemmerling (2015) work out in detail that donors face a dilemma when choosing between the total volume of aid and the amount of aid given to individual poor countries. This corresponds to a trade-off between coverage and cost of redistribution in wealthier countries. Efficient targeting becomes critical in such contexts. Fuchs and Öhler (2019) show that private donors follow the same aid allocation pattern of their respective home country. 
This result highlights the donor coordination within donor countries. Acht et al. (2015) present evidence that, if faced with high corruption and low quality of governance within recipient countries, international donors may change their strategies and decide to bypass corrupt state actors by delivering social assistance through NGOs and other nonstate actors.

These findings, however, are only based on the total volumes and sector components of foreign aid. Only scant evidence exists regarding the impact of donors on the adoption and diffusion of social transfer schemes in developing countries. For example, Maclure (1995) provides an analysis of two health programs in Burkina Faso that induce new bonds of donor dependency. Takala (1998) reveals the consistency between national education sector policy documents in four African countries and the World Bank's educational policy agenda.

These results, though illuminating, are based on qualitative research. Quantitative research on social transfers is much more scarce and generally concerns determinants of social transfers related to politics and governance, such as regime type (Dodlova et al. 2017) or rent seeking (Reinikka and Svensson 2004; Olken 2006; Dodlova et al. 2018b). To our knowledge, there does not yet exist any comparative analysis of the impact of both the characteristics of donors and policy preferences concerning the design of non-contributory social transfer programs.

Nevertheless, the growing diversity in donor strategies and approaches requires a closer look. A thorough comparative analysis of specific social policies, such as non-contributory social transfers, is necessary in order to better understand the contributions by and constraints for donors in terms of their social policy-making strategies in recipient countries. We conduct such an analysis in this chapter.

\section{Theoretical Considerations}

Our main research question aims at the extent to which the adoption and diffusion of social transfer policies in recipient countries are shaped by external donors and IFIs. To achieve this goal, we formulate three main hypotheses based on previous research and theoretical considerations. 
It is difficult to a priori disentangle the IFI's incentives and preferences, but it is possible to discover in retrospect which types and design elements of social policies are prioritized by international donors. The research hypotheses are thus formulated so as to reveal empirical patterns of donor interventions in the social policies of developing countries.

First, we argue that the type of social transfer chosen can be partially influenced by the interests of international organizations pursuing their own policy agendas. For example, UNICEF promotes family allowances and child grants, the WFP contributes to the expansion of school feeding programs and United Nations High Commissioner of Refugees (UNHCR) supports refugees and internally displaced people. It has been recognized that international donors target resources according to their own priorities (Eichenauer and Reinsberg 2016).

1. IFIs promote specific types of social transfer programs, which is partly explained by their own policy agenda priorities and/or fields of technical expertise.

Second, international institutions may support human capital development as a part of their long-term development strategies more often than national policy-makers who are more concerned with meeting short-term needs and addressing current vulnerabilities (Browne 2006). Conditional cash transfers would then be more preferred by donors than unconditional cash transfers, as the former are distributed only if certain pre-selected requirements, or the results of these requirements, are met. Often related to education, health or parental support for children below 18 , conditions might concern behavioral changes (such as school attendance) or performance (such as graduation). Such conditions entice beneficiaries to invest in human capital accumulation.

This helps to formulate the second hypothesis:

2. International donors more often favor conditional cash transfers in order to support human capital accumulation.

To confirm this prediction, we can check whether international organizations more frequently finance conditional cash transfers (CCTs). 
Some scholars have already illustrated this phenomenon, especially in Latin American countries. For example, according to Parker and Todd (2017), Mexico's Prospera, which was introduced in 1997, has influenced the design of CCTs in over 60 countries around the world, primarily with the support of the World Bank.

IFIs may play a key role in supporting certain types of social policies, not only because they provide substantial financial assistance but also because they possess the necessary expertise with poverty alleviation policies (see Devereux and Kapingidza, Chap. 11, this volume). This allows recipients to adopt more complex pro-poor policies that require a higher administrative capacity. This partly confirms Hypothesis 2, as the introduction and enforcement of conditionalities may be costly or socially challenging. For example, Schubert and Slater (2006) argue that contextual differences between Africa and Latin America in public service provision, capacity and the benefit-cost ratio of the conditionalities may have led to the broad expansion of CCTs in Latin America, while their introduction has remained inappropriate in a lower-capacity African context. Consequently, we cannot directly test which channel is more influential with the promotion of CCTs by international donors: prioritizing human capital development or institutional capacity building. We can, however, isolate the effect of capacity and expertise by focusing on one element of the program design, such as beneficiary selection or targeting. This element of the design indeed requires a substantial administrative capacity and operationalization. Thus, the donors' contributions to the implementation of the program lead to the formulation of the next hypothesis about the type of targeting mechanisms used for determining the eligibility of beneficiaries and providing them with transfers:

3. IFI support allows recipient countries to implement more complex targeting mechanisms.

The components of the donor-recipient relationship prove to be relevant for the policy choices of recipient countries. The frequency of communication, usefulness of policy advice, and helpfulness in implementation may serve as proxies for technological expertise and professional support provided by donors in recipient countries. 
The next section introduces the data and preliminary descriptive evidence which already highlights some findings that are further confirmed by the quantitative analysis in the following Sections.

\section{Data}

Several recent data sets are used for analyzing the impact of donors on the design of social policy in developing countries. First, we extract the information on social transfers from the non-contributory social transfer programs (NSTP) data set Version 1.1 created by Dodlova, Giolbas and Lay $(2017,2018 \mathrm{a})$. The database contains the main elements of the design of more than 186 social transfer schemes in 101 developing countries from 1960 to 2015. The second source is the UNU-WIDER Social Assistance, Politics and Institutions (SAPI) database. It provides the detailed characteristics, institutionalizations and budgets of 221 social assistance programs in developing countries from 2000 to 2015. More specifically, from both databases we extract information on the types of social transfers and targeting mechanisms used to define the beneficiary base as well as information on the donors or partial assistance provided by the IFIs, which is available for every social transfer program. This allows us to compile a data set which covers the most prominent trends in donor influence on social policy diffusion in developing countries.

We primarily base our results on the NSTP database, as it provides more detailed information on the types of donors participating in the adoption and/or funding of social assistance programs. Based on this information, we determine that about $35 \%$ of programs have been initiated or partially funded by at least one donor. Among the most influential donors are the World Bank, UNICEF, EU Commission, WFP and DFID UK. Our empirical analysis investigates the heterogeneity of influence by these donors. The main variables of interest are the dummies specifying that at least one donor participates in financing a social transfer program or a particular donor participates in the funding process. Thus, the coding is based on a donor's financial contribution to a social transfer policy. In total, we have six dummies, one for any donor contribution and one additional dummy for each of the major IFIs: the World Bank, UNICEF, 
EU Commission, WFP and DFID UK. If a program is funded by two or more donors, then each dummy for a respective donor equals 1 .

We focus on the impact of international actors on three main outcomes:

- type of social policy (CCTs, family support, social pensions, public works);

- conditionalities (conditional vs. unconditional programs);

- targeting method (community-based, categorical, means testing, proxy means testing, geographical, self-targeting).

Following Barrientos (2013), Ellis, Devereux and White (2009), and Coady et al. (2004a, b), we distinguish between four main types of social assistance and six targeting mechanisms. Specifically, we consider social pensions or old-age grants, unconditional family support, CCTs and employment guarantee schemes or public works programs. Based on the NSTP and SAPI databases, we present all types of social transfer programs based on this classification in Table 8.1. If a program shows elements of several types, this is taken into account by coding every type of transfer with a dummy variable. We focus on CCTs which imply that beneficiaries should not only keep edibility rules but also follow certain behavioral rules. In both data sets, the share of CCTs with at least one donor involved is quite high compared with other types of transfers.

Table 8.1 Number of programs with and without donor assistance by type in the year of starting them

\begin{tabular}{llll}
\hline NSTP & & & \\
\hline & No donor & With donor & Total \\
\hline CCT & 45 & 18 & 63 \\
Pension & 39 & 4 & 43 \\
Family support & 48 & 24 & 72 \\
Public works & 12 & 10 & 22 \\
SAPI & & & \\
& No donor & With donor & Total \\
CCT & 21 & 39 & 60 \\
Pension & 57 & 5 & 62 \\
Family support & 32 & 29 & 61 \\
Public works & 9 & 13 & 22 \\
\hline
\end{tabular}


Furthermore, in the SAPI data set the number of CCTs involving donor assistance is even higher than the number of CCTs without any donor assistance. There is consistency between the two data sets in the number of pensions and family allowances with and without donor involvement. IFIs are more active in assisting CCTs, family support programs and public works programs but not social pensions.

Figure 8.1 more clearly illustrates that IFI involvement in the assistance of social transfer schemes is quite heterogeneous. Support by the EU Commission and the WFP includes only two types of programs, namely family allowances and public works. Social pensions are assisted by the World Bank and UNICEF, while CCTs are only promoted by the World Bank, DFID UK and UNICEF.

Six targeting methods were identified. Categorical and geographical targeting combine all transfers based on a group characteristic such as age, gender, social status or place of residence. For example, social pensions make extensive use of the categorical selection of beneficiaries. Geographical selection is often applied to identify entire regions with the highest poverty rates, lowest consumption measures or extreme food deficits. Self-targeting implies that all citizens have an opportunity to receive assistance if they apply, however in principle, only those most in need

\section{Donor Assistance and Type of Transfer}

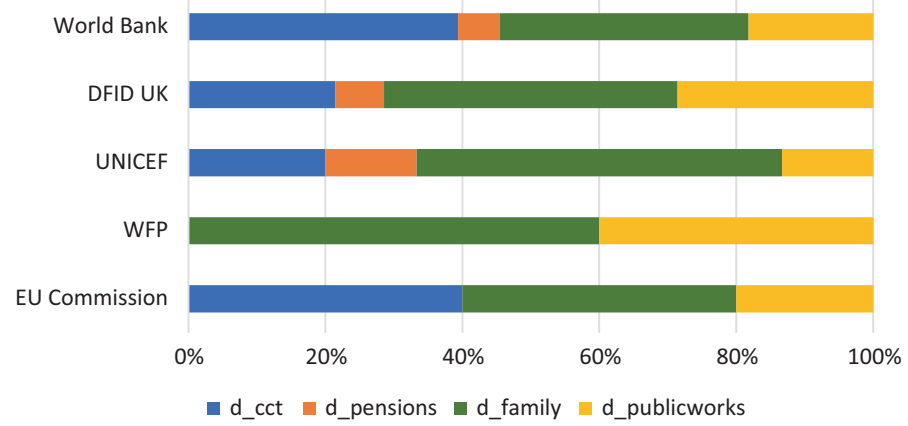

Fig. 8.1 Donor assistance and type of transfer. (Compiled by the author on the basis of the NSTP database. If a program is supported by two or more donors, then a donor with a large share of assistance is considered) 
should benefit from the program. Less needy individuals are discouraged from participating in the program by offering beneficiaries an inferior good, such as yellow maize, or by setting the wages for public works below the market level. Other types of targeting are implemented with the purpose of assessing the income level and identifying the potential beneficiaries, based on whether their income falls below a certain cut-off. Under means testing the households self-report their incomes or a program official categorizes them into income or poverty groups. The information provided might be verified through tax records or asset ownership, or it might not be verified at all — though this may increase targeting errors. Proxy means testing is similar to means testing but is more justified, as it is based on more than one indicator of income and typically makes use of the observable characteristics of the households to construct a wealth or income score. The score is then used to determine the household's eligibility for social assistance. The community-based approach is applied if a group of community representatives or head of a community decides on household eligibility for benefits. This method can make targeting more efficient, as it relies on local expertise and better information on poverty within a community at a lower cost. Additionally, the final decisions are generally more supported by the community members, which allows for avoiding potential conflicts among program participants and non-participants.

Targeting methods also differ among the programs with and without donor assistance. Figure 8.2 shows that means testing is practically unused by programs with donor assistance. Donors are typically involved in programs with proxy means testing, community-based, or geographical targeting, and a bit less in categorical and self-targeted schemes. Furthermore, a combination of targeting methods is more often used for programs with donor assistance, which might be due to a higher capacity requirement. Figure 8.3 displays the choice of targeting methods by different donors. The World Bank uses all methods, but proxy means testing dominates and geographical and community-based targeting are used extensively. UNICEF and DFID UK also apply all methods of beneficiary selection, except means testing.

This descriptive evidence already provides some insights into the preferences of international donors in terms of social policies. We are 


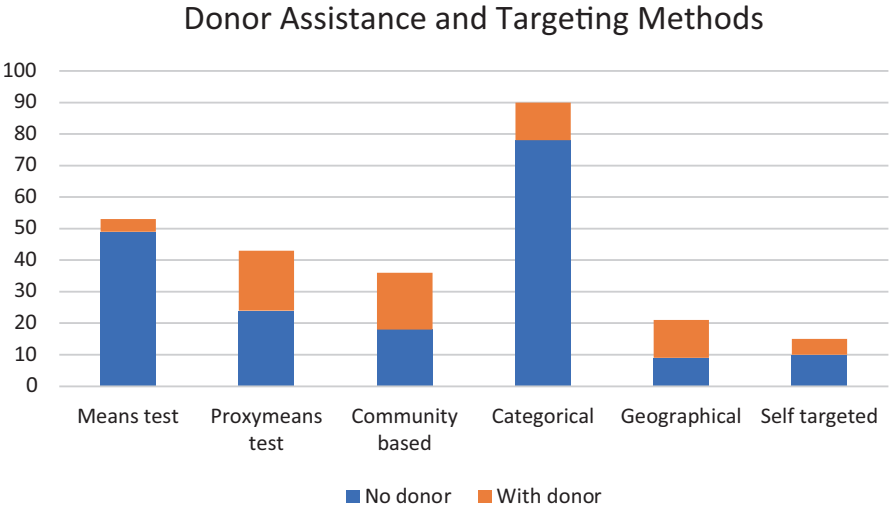

Fig. 8.2 Donor assistance and targeting methods. (Compiled by the author on the basis of the NSTP database)

\section{Targeting Methods Employed by Different Donors}

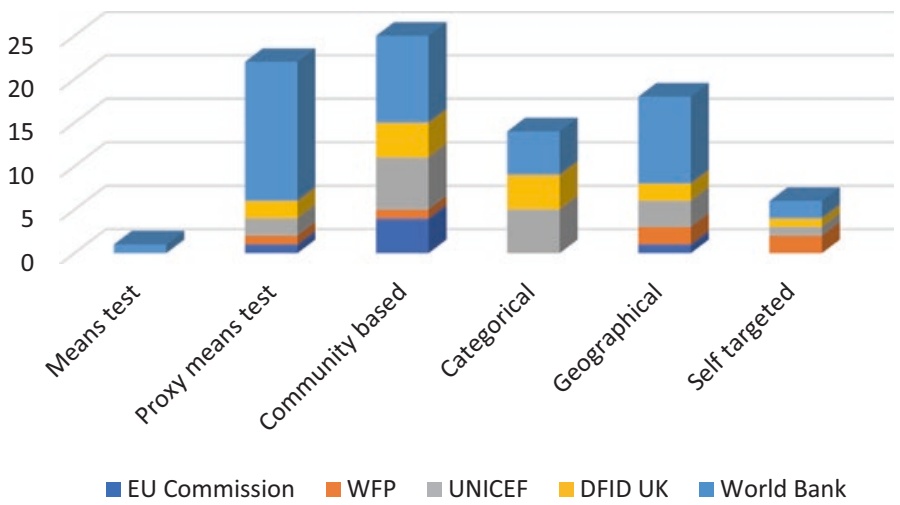

Fig. 8.3 Targeting methods employed by different donors. (Compiled by the author on the basis of the NSTP database)

now going to empirically test each hypothesis, using the data on noncontributory social transfer schemes in developing countries. The next Section presents the econometric methodology used for checking the hypotheses, and the following Section reports and discusses the main regression results. 


\section{Methodology}

To estimate the influence of donors on the types of programs implemented and targeting methods employed we use a duration model focusing on the transfer adoption process. We conduct the empirical analysis at a program level and cut the sample at the starting year of program operation. This approach allows us to mitigate endogeneity and serial correlation problems. Once a transfer program is in place, it is presumably difficult to stop its operation. Moreover, IFIs are typically involved from the year a transfer program begins and continues to support the program, due to long-term relationships between donors and recipient countries. Thus, our approach emphasizes donor assistance at the year of the adoption of a transfer program. We introduce a binary variable that equals 1 if any donor is involved in the year of the adoption of a transfer program and 0 otherwise. All years after the adoption of a program are coded as missing.

This approach is chosen primarily because, during the operation of a program, it is hard for donors to terminate assistance. National governments prove resistant to donor exit after program implementation because of the implied reduction in budget and loss of administrative support. In the NSTP data set, the information on donors remains constant over time. In the SAPI data set, only six programs have 'survived' after the donors' exit.

Our dependent variables are dummies for each of four types of social transfer programs and for each of six types of targeting methods. We assume that specific types of transfers or targeting methods illustrate donor interests in shaping social policies in developing countries. The period considered is from 1960 to the year of the adoption of each program. Hence, we focus on the adoption process of social transfer programs and the role of donors in this process. We include in the sample only those countries where at least one program has been in operation.

Among different controls included in all specifications, there are country-economic and demographic characteristics taken from the World Bank Development Indicators Database. The level of GDP per capita in millions (constant USD) is included to capture the fact that richer countries introduce more social transfer programs. To account for the popula- 
tion structure, three standard demographic controls are used: total population (in mln.), share of the population living in urban areas and age-dependency ratio. A rising age-dependency ratio means that fewer people belong to the labor force and, consequently, that fewer people pay taxes and finance redistributive and pro-poor policies. Dependence on the agricultural sector and natural resources are captured by the value added in GDP that comes from agriculture and by total natural resource rents, respectively. All of these control variables are taken in logarithms and one period lags.

To measure the regime type, we make use of the polity variable of the Center for Systemic Peace's POLITY IV project by Marshall, Gurr and Jaggers (2017). It extends until 2016 and assesses countries on a scale from -10 for a strong autocracy to +10 for a fully consolidated democracy. We take into account a diffusion process by controlling the total number of programs of each respective type or targeting method within a region in a previous year. We also control whether any other programs have previously been introduced in the country by including the number of social transfer schemes in operation in a previous period. We model unobserved heterogeneity by including country and time fixed effects. Our main empirical strategy is a standard linear probability model, because of fixed effects which add a set of dummies with a linear relationship. We also consider a logistic model, but the results do not differ significantly and our findings remain robust to the choice of the functional relationship. ${ }^{2}$

\section{Do Donors Promote Specific Types of Social Transfer Programs?}

Our first hypothesis states that IFIs can contribute to social policy diffusion by promoting specific types of transfer. In Table 8.2 we summarize the results from all regressions where the dependent variable is a dummy for a social transfer of a specific type, and the main control variable of interest is

\footnotetext{
${ }^{2}$ The logistic specification estimations are available upon request.
} 
Table 8.2 Coercion by donor

\begin{tabular}{|c|c|c|c|c|}
\hline & (1) & (2) & (3) & (4) \\
\hline & CCT & Pension & Family support & Public works \\
\hline Any donor & $\begin{array}{l}0.306 * * * \\
(0.081)\end{array}$ & $\begin{array}{l}0.031 \\
(0.037)\end{array}$ & $\begin{array}{l}0.451 * * * \\
(0.081)\end{array}$ & $\begin{array}{l}0.208 * * * \\
(0.070)\end{array}$ \\
\hline GDP per cap & $\begin{array}{l}0.010 \\
(0.013)\end{array}$ & $\begin{array}{l}0.008 \\
(0.011)\end{array}$ & $\begin{array}{l}0.013 \\
(0.014)\end{array}$ & $\begin{array}{l}-0.007 \\
(0.009)\end{array}$ \\
\hline Population & $\begin{array}{l}-0.058 \\
(0.037)\end{array}$ & $\begin{array}{l}-0.047 \\
(0.033)\end{array}$ & $\begin{array}{l}-0.057 * \\
(0.036)\end{array}$ & $\begin{array}{l}-0.021 \\
(0.021)\end{array}$ \\
\hline Urban population & $\begin{array}{l}-0.006 \\
(0.015)\end{array}$ & $\begin{array}{l}-0.014 \\
(0.015)\end{array}$ & $\begin{array}{l}0.007 \\
(0.017)\end{array}$ & $\begin{array}{l}0.012 \\
(0.014)\end{array}$ \\
\hline Age dependency & $\begin{array}{l}0.001 \\
(0.032)\end{array}$ & $\begin{array}{l}-0.003 \\
(0.029)\end{array}$ & $\begin{array}{l}-0.061 * \\
(0.031)\end{array}$ & $\begin{array}{l}-0.025 \\
(0.021)\end{array}$ \\
\hline Agriculture VA & $\begin{array}{l}-0.006 \\
(0.011)\end{array}$ & $\begin{array}{l}-0.010 \\
(0.009)\end{array}$ & $\begin{array}{l}-0.006 \\
(0.011)\end{array}$ & $\begin{array}{l}-0.003 \\
(0.007)\end{array}$ \\
\hline Resource rents & $\begin{array}{l}-0.002 \\
(0.004)\end{array}$ & $\begin{array}{l}-0.002 \\
(0.003)\end{array}$ & $\begin{array}{l}-0.007 * \\
(0.004)\end{array}$ & $\begin{array}{l}0.004 \\
(0.002)\end{array}$ \\
\hline Polity dummy & $\begin{array}{l}0.006 \\
(0.006)\end{array}$ & $\begin{array}{l}0.003 \\
(0.005)\end{array}$ & $\begin{array}{l}-0.002 \\
(0.005)\end{array}$ & $\begin{array}{l}-0.004 \\
(0.005)\end{array}$ \\
\hline $\begin{array}{l}\text { Number of any } \\
\text { transfer program }\end{array}$ & $\begin{array}{l}0.018 * * \\
(0.009)\end{array}$ & $\begin{array}{l}0.013 * * \\
(0.006)\end{array}$ & $\begin{array}{l}0.002 \\
(0.007)\end{array}$ & $\begin{array}{l}0.013 * * \\
(0.006)\end{array}$ \\
\hline $\begin{array}{l}\text { Number } \\
\text { of CCTs - region }\end{array}$ & $\begin{array}{l}0.006 * * * \\
(0.002)\end{array}$ & & & \\
\hline $\begin{array}{l}\text { Number of pension } \\
\text { schemes - region }\end{array}$ & & $\begin{array}{l}0.001 \\
(0.002)\end{array}$ & & \\
\hline $\begin{array}{l}\text { Number of family } \\
\text { support } \\
\text { schemes - region }\end{array}$ & & & $(0.002)$ & \\
\hline $\begin{array}{l}\text { Number of public } \\
\text { works } \\
\text { programme - region }\end{array}$ & & & & $0.008 *$ \\
\hline Observations & 4088 & 4088 & 4088 & 4088 \\
\hline R-squared & 0.175 & 0.047 & 0.220 & 0.150 \\
\hline Number of programs & 155 & 155 & 155 & 155 \\
\hline
\end{tabular}


Table 8.2 continued

\begin{tabular}{lllll}
\hline & $(1)$ & $(2)$ & $(3)$ & $(4)$ \\
\cline { 2 - 4 } & CCT & Pension & Family support & Public works \\
\hline Country FE & Yes & Yes & Yes & Yes \\
Year FE & Yes & Yes & Yes & Yes \\
\hline All specifications are duration models with the considered period from 1960 until \\
the year a program starts. The main variable of interest is the dummy for whether \\
at least one donor provides financial or other assistance in order to implement a \\
social transfer program. All specifications include time and country fixed effects as \\
well as control variables such as log GDP per capita, log population, log urban \\
population, log age dependency, log resource rents, log value added from \\
agriculture and a democracy dummy defined by polity2 greater than 5. We also \\
control social policy diffusion by including the number of any transfer programs \\
in operation in a country in a previous year and the number of respective social \\
transfer programs in a region in a previous year. All other variables to the right, \\
with the exception of the donor assistance dummy, are taken in one period lags. \\
Robust standard errors are in parentheses $* * * 0<0.01,{ }^{* *} p<0.05,{ }^{*} p<0.1$
\end{tabular}

a dummy for at least one donor participating in financing the social transfer program. All other variables to the right are taken in one period lags.

The results make clear that donors can drive social policy diffusion in developing countries and have some preferences for certain poverty reduction policies. IFIs mostly favor CCTs, family support programs and public works, whereas social pensions are typically adopted without any donor assistance.

The fact that social pensions are primarily initiated by national governments is confirmed by many case studies (e.g. Devereux 2007; NiñoZarazúa et al. 2012). National governments can adopt social pension not only for poverty alleviation but also for strategic motives. For example, Devereux (2007) argues that in West Africa social pensions were introduced in order to buy opposition and minority support. There is little evidence that IFIs invest extensively in social pensions, with the exception of humanitarian assistance in fragile regions. Therefore, the question of how international donors contribute to the expansion of social pensions remains unclear and probably requires further investigation.

Donor involvement increases the probability of adopting a CCT by $30 \%$, a family support program by $45 \%$ and an employment guarantee scheme by $21 \%$. The number of any social transfer programs in operation in a country in a previous period and the number of programs of a 
respective type within a region in a previous period are quite significant but do not crowd out the significant effect of donor involvement.

McCord (2012) also argues that public works programs, in particular, have been developed through the use of donor funds. She states that IFIs find a way to deal with structural economic transformations by providing additional jobs to stabilize labor markets and ensure subsistence agriculture. These initiatives lead to improvements in infrastructure and means of livelihood for the extreme poor in many developing countries. Along with significant employment and welfare benefits, another reason why public works programs are popular among donors is political stability and the higher degree of social cohesion they may induce (e.g. Buhuwania et al. 2019). ${ }^{3}$

Donors finance pro-poor policy because non-contributory transfers provide not only short-term support that decreases vulnerability but also investments in long-term sustainable development. This is especially applicable to CCTs, which involve investments in human capital accumulation by ensuring school attendance or regular health check-ups. Family allowances are also promoted by donors, as they provide support for pregnant women, young children, orphans, dependent household members and others. Investments in early childhood are extremely important, as they have long-term effects on poor families and thus may contribute to sustainable development from a long-term perspective (see Chinyoka and Ulriksen, Chap. 10, this volume).

Moreover, there is heterogeneity in the policy interests of various donors. Table 8.3 reports the estimation results of the main independent variables serving as dummies for donor types. The findings confirm that donors contribute to pro-poor transfers according to their own policy agenda priorities. While the World Bank promotes all programs except for social pensions, UNICEF assists only family support programs, including cash transfer programs for vulnerable children and pregnant women in Togo, Sierra Leone, Uganda and other African countries. This makes evident that UNICEF prioritizes unconditional transfers in order to meet short-term needs in health and education. The same policy

\footnotetext{
${ }^{3}$ However, there is only limited quantitative evidence on increasing social capital as a result of public work programs. In addition, there are even controversial findings based on the qualitative analysis (see, e.g., Vajja and White 2008). Further research on this issue would be required.
} 
Table 8.3 Coercion by donor type

\begin{tabular}{lllll}
\hline & $(1)$ & $(2)$ & $(3)$ & $(4)$ \\
\cline { 2 - 5 } & CCT & Pension & Family support & Public works \\
\hline World bank & $0.410 * * *$ & 0.019 & $0.318 * * *$ & $0.209 * *$ \\
& $(0.103)$ & $(0.034)$ & $(0.094)$ & $(0.088)$ \\
DFID UK & 0.154 & 0.084 & $0.490 * * *$ & $0.420 * *$ \\
& $(0.141)$ & $(0.106)$ & $(0.156)$ & $(0.165)$ \\
UNICEF & 0.160 & 0.069 & $0.700 * * *$ & 0.190 \\
& $(0.133)$ & $(0.114)$ & $(0.149)$ & $(0.130)$ \\
EU Commission & $-0.053 * *$ & -0.014 & $0.923 * * *$ & $0.633 * *$ \\
& $(0.024)$ & $(0.015)$ & $(0.030)$ & $(0.272)$ \\
WFP & $-0.033 *$ & -0.040 & 0.221 & $0.651 * *$ \\
& $(0.019)$ & $(0.028)$ & $(0.284)$ & $(0.258)$ \\
Observations & 4088 & 4088 & 4088 & 4088 \\
Number of programs & 155 & 155 & 155 & 155 \\
Country FE & Yes & Yes & Yes & Yes \\
Year FE & Yes & Yes & Yes & Yes \\
\hline
\end{tabular}

All specifications are duration models with the considered period from 1960 until the year a program starts. The main variable of interest is the dummy for whether a certain donor or international organization provides financial assistance to implement a social transfer program. All specifications include time and country fixed effects as well as control variables such as log GDP per capita, log population, log urban population, log age dependency, log resource rents, log value added from agriculture and a democracy dummy defined by polity 2 greater than 5 . We also control for social policy diffusion by including the number of any transfer programs in operation in a country in a previous year and the number of respective social transfer programs in a region in a previous year. All other variables to the right, with the exception of the donor type, are taken in one period lags and their coefficients are not displayed. Robust standard errors are in parentheses. ${ }^{* * *} p<0.01,{ }^{* *} p<0.05,{ }^{*} p<0.1$

strategy is pursued by the EU Commission. UNICEF's and EU Commission's support for family allowances increases by $25 \%$ and $45 \%$ in comparison with any donor assistance.

Interestingly, DFID UK, the EU Commission and the WFP do not favor CCTs and instead prefer direct investments in human capital such as family support and public works programs. In general, conditionalities are promoted only by the World Bank, which might be due to the difficulty of enforcement and lower state capacity in recipient countries. In case of CCTs, the effect is even higher for the involvement of the World Bank than for any donor involvement and makes as much as $40 \%$. Other case studies confirm this finding. According to Pick et al. (2019), the World 
Bank is regarded as a key donor and has influenced the expansion of CCTs in developing countries. ${ }^{4}$ In particular, because of the World Bank's support for CCTs, Prospera was able to become the model for the design of CCTs in more than 60 countries around the world (Parker and Todd 2017). CCTs also require some behavioral rule compliance and thus might not be optimal under emergency conditions, so most donors do not consider such programs to be among the necessary tools for social protection. CCTs prove to be more effective in promoting long-term, sustainable development, so the involvement of the World Bank can also be explained by its priority for developing infrastructure, communities/ cities and strong institutions. These interests are also confirmed through the promotion of public works by the World Bank and the EU Commission, which is also in line with the high priority both place on building infrastructure and developing communities and cities.

These findings confirm our hypotheses that donors differ in their social policy diffusion strategies. They mostly adopt policies according to their own agenda and promote specific policies such as CCTs to expand their technical expertise to developing countries. However, donor funding preferences can be analyzed further, for example, by using their contribution toward achieving the Sustainable Development Goals (SDGs) or qualitative case studies (see Künzler, Chap. 4, this volume; Chinyoka and Ulriksen, Chap. 10, this volume; Devereux and Kapingidza, Chap. 11, this volume).

\section{Is Donor Involvement Associated with Specific Targeting Methods?}

Table 8.4 shows donor influence on the design of social transfer programs, specifically the targeting method used to determine the beneficiary base. Interestingly, the preferences of almost all international organizations are consistent for programs that use community-based targeting. This way of beneficiary selection is strongly favored by all donors except for the WFP. Community-based targeting is considered to be one of the most

\footnotetext{
${ }^{4}$ https://www.oecd.org/dev/inclusivesocietiesanddevelopment/Lessons_learned_social_development_partners_for_social_protection.pdf.
} 


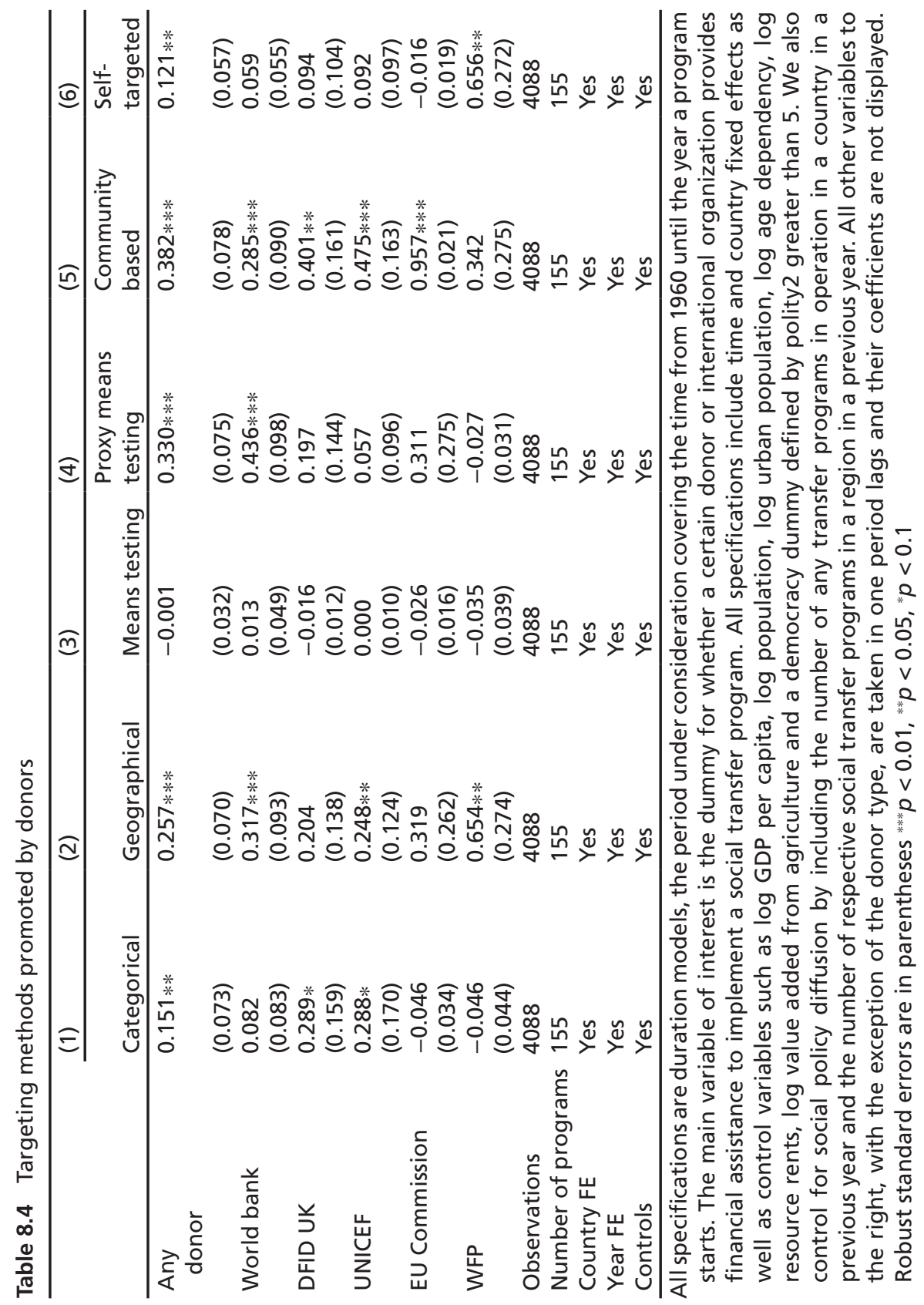


effective methods, as it allows for the use of local information regarding the level of poverty and helps with avoiding social conflicts. On the other hand, as this type of targeting does not always yield an unbiased selection of the most vulnerable individuals, it can also increase local capture (Conning and Kevane 2002).

Any donor participation is an insignificant predictor of means testing targeting, which is typically employed in programs funded by national governments. This result is driven by the fact that very few means testing programs are adopted with any donor involvement (see Fig. 8.2). Thus, our evidence confirms that national governments broadly use this method of beneficiary selection, probably because of its clarity and relatively easy operationalization.

At the same time, proxy means testing is promoted by donor involvement, and especially by the World Bank, which is probably related to the technical expertise and administrative capacity required. Because of its non-transparency, proxy means testing allows for the exclusion of any political manipulations and rent seeking and so might be preferred by the World Bank in order to assure the efficiency and impartiality of social transfers.

DFID UK and UNICEF often use categorical targeting, as they primarily focus on family support programs. More specifically, the involvement of DFID UK and UNICEF increases the probability of using categorical targeting by 30\%. Geographical targeting is applied by the World Bank, UNICEF and the WFP to target the poorest and most vulnerable regions. This method might be especially efficient for targeting areas in the aftermath of shocks and crises, which is a priority for both UNICEF and the WFP. For example, the WFP's assistance is associated with the more frequent use of geographical targeting by about $60 \%$. The promotion of self-targeted programs by the WFP might also be related to the offering of inferior quality food in times of crisis. The probability of using this type of beneficiary selection in case of the WFP also makes as much as $60 \%$.

Technical assistance and expertise of international donors might be essential for applying specific targeting methods to social protection policies. Donors can contribute to the development and implementation of the Management Information Systems (MIS), the Harmonized Targeting 
tools and the Unified Beneficiary Registries (UBR). For example, Malawi's Social Cash Transfer Programme (SCTP) has benefited from UNICEF's support of the pilot project and further from the assistance of the German Institute for International Cooperation (GIZ) and KfW Development Bank in the design and implementation of the targeting system. ${ }^{5}$ SCTP uses a mix of categorical, community-based targeting and proxy means testing. Another good example is a Yemen Emergency Crisis Response Project (ECPR) that has provided transfers to the citizens of Yemen during an active conflict using geographical and multi-layered proxy means testing targeting. The project was grounded on the pre-existing national system of social transfers in a close interaction with the Yemen Social Fund for Development (SFD) and the Public works Project (PWP). The operational introduction of a complex system of targeting became possible with the support of the World Bank, UNDP and UNICEF.

Regarding the targeting mechanisms, the basic intuition is that the more influential donors are, the more can they promote more complex systems of beneficiary selection. This might be the case for the World Bank, which has abundant operational capacity and about 180 branches in developing countries. This can also help with explaining its preference for proxy means testing, which can be very effective for detecting the chronically poor (Grosh et al. 2008) but is difficult to realize, as it requires high institutional and statistical capacity. Hence, we can confirm our third hypothesis and therefore emphasize the importance of donor support in the design and implementation of social policies in recipient countries. Community-based targeting is preferred by all donors, probably due to the necessity of involving community agents and local chiefs in targeting and monitoring, but also for controlling their performance in order to avoid potential eligibility manipulation and local capture. Categorical selections are low-capacity measures that are widely used by DFID UK and UNICEF, but this is probably related to their general policy agendas that prioritize support for poor families and children. Geographical targeting is popular among almost all donors, but it is typically applied together with other selection methods like community-based targeting or proxy means testing. These consider-

\footnotetext{
${ }^{5}$ https://www.giz.de/de/downloads/Poverty\%20Targeting\%20Primer_Full\%20Version.pdf.
} 
ations are based on development performance and help with highlighting how certain aspects of donor-recipient interactions shape social policy in developing countries.

\section{Discussion and Conclusion}

The revelation of policy patterns pursued by international donors may help to a better understanding of development policy failures and with improving future development interventions. These findings provide important insights into how donors influence social policies, specifically non-contributory social transfer schemes.

Our findings suggest that IFIs have some preferences concerning which transfer types and targeting mechanisms are adopted. At the same time, their impacts appear to be generally in line with long-term development goals. Donors promote programs which either support families in emergency situations or imply investments in long-term human capital accumulation, such as CCTs or employment guarantee schemes. There is also some heterogeneity among donors. While the World Bank more frequently develops CCTs, UNICEF focuses primarily on family allowances to small children and pregnant women. This is consistent with the general goals and strategies of these financial institutions. It is interesting to note that social pensions, including old-age grants and disability pensions, are not favored by any donor. This reflects the general perspective that these policies are meant for short-term emergency assistance and are therefore not designed to structurally alleviate poverty.

In addition to the type of social transfer program, specific targeting methods are also promoted by different IFIs. Policy effectiveness might be fully undermined if the identification of the extreme poor and the selection of transfer beneficiaries are not correctly carried out. Hence, the choice of targeting method might be strategic, as donors typically finance social policies under the condition that social assistance is adequately distributed. This intuition is partly confirmed by our results, as international donors support either very transparent methods of selection, such as categorical or geographical targeting, or complex identification methods such as proxy means testing in order to avoid eligibility manip- 
ulation. Self-selection remains a popular method among donors, which is consistent with the high share of CCTs supported by IFIs. However, the most promoted method, community-based targeting, typically ensures better access to information on poverty status at the local level. Administrative costs and information asymmetries can be reduced by using community agents such as local chiefs or leaders of social or religious groups instead of official agents who are better qualified but less informed. The main threat connected to this type of targeting is that the community agents may pursue their own interests rather than base their analyses on the actual needs of the people (Coady and Skoufias 2004). This is also confirmed by Dodlova et al. (2018b) who show that community-based targeting is quite popular in rent-seeking societies. International donors should take such threats into consideration when supporting social policies in developing countries.

Valuable lessons can be learned from these insights. First, international donors should keep an eye on policy formulation. For example, Khan et al. (2018) find that donors have three different channels of influencing health policies in Cambodia and Pakistan: financial resources, technical expertise and indirect financial and political incentives. Depending on the stage of the policy process, donors may provide financial, technical or evaluation expertise. Second, donors can significantly improve the implementation of any social policy, sometimes at low costs. For example, the WFP was able to build an information database to improve the process of identifying the most vulnerable populations in Colombia in 2004 and 2005. In addition to officially IDPs, the WFP could take into account other vulnerable populations through Church networks and communitybased interventions that were designed specifically to identify families affected by conflict and food insecurity. Also, donors can contribute to monitoring and evaluations which appear quite critical in tracking aid allocation. Hence, donors have all of the resources and expertise needed to design innovative, effective social policy interventions in developing countries.

What is most important is that international donors support the policy initiatives of national governments without taking the leading role in their implementation. The keystone of donor interventions should be their complementarity to national initiatives rather than their substitu- 
tion for them. In particular, donor interventions should not replace the functions of national governments and should allow them to build their own capacities.

Our results confirm that donors contribute particularly to national transfer policies that require a higher level of technical support or operationalization, such as CCTs or proxy means testing targeting. Implicitly, this illustrates that donors are adequately cautious about contributing to social policy assistance. This conclusion is consistent with other literature on social policies. For example, also Holmqvist (2012) stresses that donor policies should not serve as leverage for institutionalizing permanent social protection systems but rather support recipient countries by their initiatives. He also gives an overview of different strategies donors can pursue for their funding while still providing national governments with enough flexibility to design and implement social policies.

We implicitly assume that donors may drive the formulation and implementation of certain policies according to their own interests and priorities. For example, donors may promote specific aid allocation patterns to achieve major Millennium Development Goals (Thiele et al. 2007). However, our findings would be perfectly in line with the view that recipient countries are strategic in their involvement with respective donors. From this perspective, donors behave as benevolent actors and social planners, and national governments appeal to them for help with specific policies. It would be interesting to investigate this hypothesis via case studies and other qualitative research. Our findings may also serve as a starting point for further research, comparing the positive and negative consequences of donor influence on poverty alleviation policies in developing countries. This contribution notably does not focus on how donor involvement influences the efficiency of social transfer programs. For example, Devereux and White (2010) argue that domestic policy-makers are shown to have suggested more efficient initiatives for social policy models than have international development actors. More efficient policies imply nationwide coverage, broad political support and, oftentimes, long-term sustainability. However, the technical expertise and institutional capacity provided by donors might be essential for program implementation. Hence, there should be a balance between national interests and donor influence. Another potentially interesting topic for explora- 
tion is donor involvement in countries with different political regimes. According to Dodlova (2018a), in non-democracies almost $40 \%$ of programs are co-financed by donors as opposed to $17 \%$ in democracies. This suggests that donor influence on social policy in non-democracies is more relevant for a sustainable development, as they are more traditional and less open to policy innovations. Hence, our results can be considered a first step toward investigating many other issues related to donor involvement and influence on social policy in developing countries.

\section{References}

Acht, Martin, Toman Omar Mahmoud, and Rainer Thiele. 2015. Corrupt Governments Do Not Receive More State-to-State Aid: Governance and the Delivery of Foreign Aid Through Non-state Actors. Journal of Development Economics 114 (C): 20-33.

Alesina, Alberto, and David Dollar. 2000. Who Gives Foreign Aid to Whom and Why? Journal of Economic Growth 5: 33-63.

Allen, Susan Hannah, and Michael Flynn. 2018. Donor Government Ideology and Aid Bypass. Foreign Policy Analysis 14 (4): 449-468.

Barrientos, Armando. 2013. Social Assistance in Developing Countries. New York: Cambridge University Press.

Berthélemy, Jean-Claude. 2006. Bilateral Donors' Interest vs. Recipients' Development Motives in Aid Allocation: Do All Donors Behave the Same? Review of Development Economics 10 (2): 179-194.

Bodenstein, Thilo, and Achim Kemmerling. 2015. A Paradox of Redistribution in International Aid? The Determinants of Poverty-Oriented Development Assistance. World Development 76: 359-369.

Brech, Viktor, and Niklas Potrafke. 2014. Donor Ideology and Types of Foreign Aid. Journal of Comparative Economics 42 (1): 61-75.

Browne, Stephen. 2006. Aid and Influence. Do Donors Help or Hinder? London: Routledge.

Buhuwania, Pragya, J. Hemann, A. Mukherji, A. Nandi, and H. Swaminathan. 2019. Public Works Programs and Social Capital: An Exploration of MGNREGA in India. mimeo.

Cashel-Cordo, Peter, and Steven G. Craig. 1997. Donor Preferences and Recipient Fiscal Behavior: A Simultaneous Analysis of Foreign Aid. Economic Inquiry 35 (3): 653-671. 
Coady, David, and Emmanuel Skoufias. 2004. On the Targeting and Redistributive Efficiencies of Alternative Transfer Instruments. Review of Income and Wealth 50 (1): 11-27.

Coady, David, Margaret Grosh, and John Hoddinott. 2004a. Targeting of Transfers in Developing Countries: Review of Lessons and Experience. Washington, DC: World Bank. . 2004b. Targeting Outcomes, Redux. The World Bank Research Observer 19 (1): 61-85.

Conning, Jonathan, and Michael Kevane. 2002. Community-based Targeting Mechanism for Social Safety Nets: A Critical Review. World Development 30 (3): 375-394.

Devereux, Stephen. 2007. Social Pensions in Southern Africa in the Twentieth Century. Journal of Southern African Studies 33 (3): 539-560.

Devereux, Stephen, and Philip White. 2010. Social Protection in Africa: Evidence, Politics and Rights. Poverty and Public Policy 2 (3): 53-77.

Dodlova, Marina, Anna Giolbas, and Jann Lay. 2017. Social Transfers and Conditionalities under Different Regime Types. European Journal of Political Economy 50 (C): 141-156.

. 2018a. Non-Contributory Social Transfer Programmes in Developing Countries: A New Data Set and Research Agenda. Data in Brief 16: 51-64. . 2018b. Pro-poor versus Political Targeting: An Analysis of Social Assistance in Developing Countries. mimeo.

Dreher, Axel, Peter Nunnenkamp, and Rainer Thiele. 2008. Does US Aid Buy UN General Assembly Votes? A Disaggregated Analysis. Public Choice 136 (1-2): 139-164.

Dreher, Axel, Jan-Egbert Sturm, and James Raymond Vreeland. 2009. Development Aid and International Politics: Does Membership on the UN Security Council Influence World Bank Decisions? Journal of Development Economics 88 (1): 1-18.

Dreher, Axel, Peter Nunnenkamp, and Maya Schmaljohann. 2015. The Allocation of German Aid: Self-interest and Government Ideology. Economics and Politics 27 (1): 160-184.

Dreher, Axel, Vera Z. Eichenauer, and Kai Gehring. 2018. Geopolitics, Aid and Growth: The Impact of UN Security Council Membership on the Effectiveness of Aid. World Bank Economic Review 32 (2): 268-286.

Dreher, Axel, Andreas Fuchs, Roland Hodler, Bradley C. Parks, Paul A. Raschky, and Michael J. Tierney. 2019. Aid on Demand: African Leaders and the Geography of China's Foreign Assistance. Journal of Development Economics 140: 44-71. 
Eichenauer, Vera Z., and Bernhard Reinsberg. 2016. What Determines Earmarked Funding to International Development Organizations? Evidence from the New Multi-bilateral Aid Data. Center for Comparative and International Studies (CIS), Working Paper No. 88.

Ellis, Frank, Stephen Devereux, and Philip White. 2009. Social Protection in Africa. Cheltenham and Northampton, MA: Edward Elgar.

Faye, Michael, and Paul Niehaus. 2012. Political Aid Cycles. The American Economic Review 102 (7): 3516-3530.

Fuchs, Andreas, and Hannes Öhler. 2019. Does Private Aid Follow the Flag? An Empirical Analysis of Humanitarian Assistance. mimeo.

Fuchs, Andreas, and Katharina Richert. 2018. Development Minister Characteristics and Aid Giving. European Journal of Political Economy 53: 186-204.

Fuchs, Andreas, Axel Dreher, and Peter Nunnenkamp. 2014. Determinants of Donor Generosity: A Survey of the Aid Budget Literature. World Development 56: 172-199.

Grosh, Margaret, Carlo del Ninno, Emil Tesliuc, and Azedine Ouerghi. 2008. For Protection and Promotion: The Design and Implementation of Effective Safety Nets. Washington, DC: World Bank.

Groves, Leslie, and Rachel Hinton, eds. 2013. Inclusive Aid: Changing Power and Relationships in International Development. London: Routledge Press.

Hagen-Zanker, Jessica, and Anna McCord. 2013. The Affordability of Social Protection in the Light of International Spending Commitments. Development Policy Review 31 (4): 397-418.

Harrigan, Jane, Chengang Wang, and Hamed El-Said. 2006. The Politics of IMF and World Bank Lending: Will it Backfire in the Middle East and North Africa? In The IMF, World Bank and Policy Reform, ed. Alberto Paloni and Maurizio Zanardi, 64-99. New York: Routledge.

Hicks, Daniel L., Joan Hamory Hicks, and Beatriz Maldonado. 2016. Women as Policy Makers and Donors: Female Legislators and Foreign Aid. European Journal of Political Economy 41: 46-60.

Holmqvist, Göran. 2012. External Financing of Social Protection: Opportunities and Risks. Development Policy Review 30 (1): 5-27.

Khan, Mishal S., Ankita Meghani, Marco Liverani, Imara Roychowdhury, and Justin Parkhurst. 2018. How do External Donors Influence National Health Policy Processes? Experiences of Domestic Policy Actors in Cambodia and Pakistan. Health Policy and Planning 33 (2): 215-223. 
Kilby, Christopher. 2006. Donor Influence in Multilateral Development Banks: The Case of the Asian Development Bank. The Review of International Organizations 1 (2): 173-195.

Maclure, Richard. 1995. Primary Health Care and Donor Dependency: A Case Study of Nongovernment Assistance in Burkina Faso. International Journal of Health Services 25 (3): 539-558.

Marshall, Monty G., Ted Robert Gurr, and Keith Jaggers. 2017. POLITY IV Project: Political Regime Characteristics and Transitions, 1800-2016. Center for Systemic Peace.

McCord, Anna. 2012. The Politics of Social Protection: Why Are Public Works Programmes So Popular with Governments and Donors? Overseas Development Institute.

Milner, Helen V., and Dustin H. Tingley. 2010. The Political Economy of U.S. Foreign Aid: American Legislators and the Domestic Politics of Aid. Economics and Politics 22 (2): 200-232.

Minasyan, Anna, Peter Nunnenkamp, and Katharina Richert. 2017. Does Aid Effectiveness Depend on the Quality of Donors? World Development 100: 16-30.

Niño-Zarazúa, Miguel, Armando Barrientos, Samuel Hickey, and David Hulme. 2012. Social Protection in Sub-Saharan Africa: Getting the Politics Right. World Development 40 (1): 163-176.

Non-Contributory Social Transfer Programmes (NSTP) in Developing Countries Data Set v1.1. 2017. [Online] Dodlova, Marina, Anna Giolbas and Jann Lay. http://doi.org/10.7802/1530.

Olken, Benjamin A. 2006. Corruption and the Costs of Redistribution: Micro Evidence from Indonesia. Journal of Public Economics 90 (4-5): 853-870.

Parker, Susan Wendy, and Petra E. Todd. 2017. Conditional Cash Transfers: The Case of Progresa/Oportunidades. Journal of Economic Literature 55 (3): 866-915.

Pick, Alexander, Alexandre Kolev, and Ji-Yeun Rim. 2019. Optimising the Role of Development Partners for Social Protection. OECD.

Reinikka, Ritva, and Jakob Svensson. 2004. Local Capture: Evidence from a Central Government Transfer Program in Uganda. The Quarterly Journal of Economics 119 (2): 679-705.

Schubert, Bernd, and Rachel Slater. 2006. Social Cash Transfers in Low-Income African Countries: Conditional or Unconditional? Development Policy Review 24 (5): 471-478. 
Takala, Tuomas. 1998. Making Educational Policy under Influence of External Assistance and National Politics-A Comparative Analysis of the Education Sector Policy Documents of Ethiopia, Mozambique, Namibia and Zambia. International Journal of Educational Development 18 (4): 319-335.

Thérien, Jean-Philippe, and Alain Noel. 2000. Political Parties and Foreign Aid. American Political Science Review 94 (1): 151-162.

Thiele, Rainer, Peter Nunnekamp, and Axel Dreher. 2007. Do Donors Target Aid in Line with the Millennium Development Goals? A Sector Perspective of Aid Allocation. Review of World Economics 143 (4): 596-630.

UNU-WIDER. 2018. Social Assistance, Politics, and Institutions (SAPI) Database [Online]. Helsinki: United Nations University World Institute for Development Economics Research (UNU-WIDER). https://www.wider. unu.edu/project/sapi-social-assistance-politics-and-institutions-database.

Vajja, Anju, and Howard White. 2008. Can the World Bank Build Social Capital? The Experience of Social Funds in Malawi and Zambia. Journal of Development Studies 44 (8): 1145-1168.

Vreeland, James Raymond, and Axel Dreher. 2014. The Political Economy of the United Nations Security Council: Money and Influence. New York: Cambridge University Press.

World Development Indicators. Washington, DC: The World Bank.

Open Access This chapter is licensed under the terms of the Creative Commons Attribution 4.0 International License (http://creativecommons.org/licenses/ by/4.0/), which permits use, sharing, adaptation, distribution and reproduction in any medium or format, as long as you give appropriate credit to the original author(s) and the source, provide a link to the Creative Commons licence and indicate if changes were made.

The images or other third party material in this chapter are included in the chapter's Creative Commons licence, unless indicated otherwise in a credit line to the material. If material is not included in the chapter's Creative Commons licence and your intended use is not permitted by statutory regulation or exceeds the permitted use, you will need to obtain permission directly from the copyright holder.

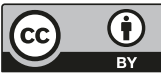

